by-pass. J Hosp Infect 1995;31:285-293.

28. Dominguez MA, Linares J, Pulido A, Perez JL, de Lencastre $H$ Molecular tracking of coagulase-negative staphylococcal isolates from catheter-related infections. Microb Drug Resist 1996;2:423-429.

29. Martin DM, Vindel A, Offez-Nieto JA. Epidemiological typing of clinically significant strains of coagulase-negative staphylococci.J Hosp Infect 1995;29:35-43.

30. Barcs I, Paszti J, Czirok E. Typing of coagulase-negative staphylococci isolated from immunocompromised patients. Acta Microbiologica et Immunologica Hungarica 1994;41:163-172.

31. Zaidi AK, Harrell LJ, Rost JR, Reller LB. Assessment of similarity among coagulase-negative staphylococci from sequential blood cultures of neonates and children by pulsed-field gel electrophoresis. $J$ Infect Dis 1996;174:1010-1014.

32. Toldos CM, Yague G, Ortiz G, Segovia M. Assessment of multiple coagulase-negative staphylococci isolated in blood cultures using pulsed-field gel electrophoresis. Eur J Clin Microbiol Infect Dis 1997; 16:581-586.

33. Koneman EW, Allen SD, Janda WM, Schreckenberger PC, Winn SC. Color Atlas and Textbook of Diagnostic Microbiology. 5th ed. Philadelphia, PA: Lippincott-Raven; 1997:539-566.

34. Weinbaum FI, Lavie S, Danek M, Sixsmith D, Heinrich GF, Mills SS. Doing it right the first time: quality improvement and the contaminant blood culture. J Clin Microbiol 1997;35:563-565.

\title{
FDA Holds Open Meeting on Reuse of Single-Use Devices
}

\section{Gina Pugliese, RN, MS Martin S. Favero, PhD}

On December 14, 1999, the FDA held an open meeting in Rockville, Maryland, to solicit input to decide the best way to regulate reuse of single-use devices.

Linda Kahan, Deputy Director, FDA's Center for Devices and Radiologic Health (CDRH), noted that reuse of single-use devices is a complicated issue with medical, legal, ethical, and economic ramifications. Kahan recognized that reuse of single-use devices appears to be a growing trend and that an increasing variety of products labeled "single use" are being used more than once. Further, Kahan noted that the FDA likely can identify a group of single-use devices that can be reused safely following tested and validated cleaning and sterilization processes. Conversely, the FDA believes that there are products whose reuse probably poses significant risk.

The FDA has developed a pro- posed regulatory approach that uses risk as its primary focus with different enforcement strategies applied to different devices depending on the potential risk. Under the FDA proposal, a three-tiered system would be used to categorize single-use devices as high, moderate, or low risk. This system would be based on the FDA's regular classification system and also factor in what is known about the risk of infection and the complexity of reprocessing procedures associated with different devices.

Following public statements from national groups and interested healthcare professionals, and workshop discussions of key issues, Dr. Larry Kessler, Director, Office of Surveillance and Biometrics, CDRH, provided an overview of what was discussed at the meeting and outlined next steps. Kessler also mentioned issues brought up during the meeting that do not fall within the FDA's mission, including the potential economic issues related to the reuse of single-use devices, the ethics involved in reuse, and the global implications of reuse.

Dr. Kessler outlined issues that need to be addressed before a comprehensive regulatory strategy can be put in place, including clarifying a plan of action; developing guidance on sterility validation; developing guidance on registration and listing for healthcare facilities; reviewing the guidance on assessing the risk of single-use devices; reaching out to industry, healthcare facilities, clinicians, and the public; using quality systems in the context of reuse; developing auditing programs; developing regulation on labeling single-use devices; continuing to receive, catalog, and analyze scientific data; and helping to develop horizontal and vertical standards relating to the reuse of singleuse devices.

Kessler said that work is ongoing and $\mathrm{CDRH}$ will make resolution of the reuse issue a priority in the year 2000 . FDA documents related to the reuse of single-use devices can be found on the CDRH web site at http://www.fda.gov/ cdrh/reuse/index.html. 